\title{
Incidence of Avian Mycoplasmosis in the region of Batna, Eastern Algeria
}

\author{
Heleili, N. ${ }^{1}{ }^{1}$ Mamache, B. ${ }^{1}$ and Chelihi, $A{ }^{2}$ \\ 1. Laboratory of microbiology, veterinary department, Hadj Lakhdar University, Batna, Algéria \\ 2. Veterinary surgeon, commune de sefiane 05064, Ngaoues, Batna-Algéria \\ * Corresponding author email : rbeddiaf@hotmail.com
}

\begin{abstract}
Avian mycoplasmosis is infectious and contagious disease which affects chicken and turkey as well as many other species with many economics losses. The absence of data on avian mycoplasmosis in Algeria and the importance of the poultry breeding in Batna encouraged us to undertake the prevalence of the most pathogenic mycoplasmas in broiler and layer chickens in this area, Mycoplasma gallisepticum (MG). 143 Mycoplasmas were isolate from 237 samples, at a rate of $60.33 \%$. MG was isolate at a rate of $21.67 \%$ (2.09\% in layer hens and $19.58 \%$ in broiler chickens). The serological screening using of breedings showed a sensitivity of $83.10 \%$. This study shows that mycoplasmosis and in particular MG infection, represent a serious problem in chickens in Algeria in the absence of hygiene conditions and vaccination especially.
\end{abstract}

Key words: Mycoplasma gallisepticum, Growth inhibition test, Seroprevalence, Broiler chickens, laying hens, Mycoplasmosis, Avian Disease.

\section{I ntroduction}

Avian mycoplasmosis is caused by several pathogenic mycoplasmas of which Mycoplasma gallisepticum (MG) and Mycoplasma synoviae (MS) are the most important. MG causes chronic respiratory disease of domestic poultry especially in the management stresses and/or other respiratory pathogens. Disease is characterized by coryza conjunctivitis sneezing and sinusitis particularly in turkeys. It can result in loss of production and downgrading of meat-type birds and loss of egg production. MS may cause respiratory disease synovitis or may result in a silent infection. MG and MS strains vary in infectivity and virulence and infections may sometimes be unapparent (Bradbury, 2001; Ley, 2003; OIE, 2008).

The frequent occurrence of unspecified clinical signs of respiratory disease among poultry flocks in Batna region and the lack of data on the role of mycoplasmas in these diseases had encouraged us to undertake this investigation.

The aim of this study was to evaluate the prevalence of MG infection in broilers and laying hens in the region of Batna (Eastern Algeria) using the rapid slide agglutination test and the isolation and identification method. Among 237 analyzed samples MG was isolate at a rate of $21.67 \%$ of which $2.09 \%$ in laying hens and $19.58 \%$ in broilers.

\section{Material and Methods}

Our study was conducted between October 2008 and September 2010 in 23 flocks divided as follows: laying hens $(n=11)$, broiler chickens $(n=13)$. These farms were divided into 10 districts of the wilaya of Batna. Birds collected during this investigation were apparently healthy or with respiratory lesions of lung, air sacs, or trachea. The number of poultry per farm varied between 3000 and 5000. Broilers were reared in the soil over a straw litters. Laying hens were caged. It should be noted that the density standards, ventilation and hygiene were exceptionally observed.

Sampling: 148 of blood samples were taken as follows:

69 blood samples from laying hens

79 blood samples from broiler-chickens.

After coagulation during 2 hours at room temperature, the serum is centrifuged at $1500 \mathrm{tr} / \mathrm{min}$ for $15 \mathrm{~min}$ and inactivated at $56^{\circ} \mathrm{C}$ for $30 \mathrm{~min}$. then the serum is diluted to $1 / 5$ to reduce non specific and cross-reactions between MG and MS.

All serum are put in sterile aliquots and maintained at $4^{\circ} \mathrm{C}$ until use within the following 48 hours.

Bacteriology: For the bacteriological diagnostic, 237 samples of tracheas, lungs and air sacs were taken from recently dead birds or those dead frozen until use (Evans et al., 2009). 
Incidence of Avian Mycoplasmosis in the region of Batna, Eastern Algeria

Table-1. Serological and bacteriological results of Mycoplasma gallisepticum infection

\begin{tabular}{lll}
\hline Chicken & Serology & Bacteriology \\
\hline Laying hens & $56 / 69(81.15 \%)$ & $3 / 87(2.09 \%)$ \\
Broiler chickens & $67 / 79(84.81 \%)$ & $28 / 150(19.58 \%)$ \\
Average & $83.10 \%$ & $13.08 \%$ \\
\hline
\end{tabular}

Culture medium of mycoplasmas: Liquid and solid Frey`s medium was used for the isolation of mycoplasmas (Frey et al., 1968). It consist of PPLO broth base $(2.1 \%)$ and PPLO agar (1\%) (Difco Laboratories).

The media base was enriched with $15 \%$ horse serum; $1 \%$ of glucose; and $10 \%$ yeast extract. Contamination of media was prevented by adding $1 \%$ thallium acetate and $0.5 \%$ penicillin $G$ potassium.

Serology: The detection of antibodies against $\mathrm{MG}$ was achieved by the rapid slide agglutination method.MG antigen was kindly supplied by $\mathrm{Dr}$ Bouchardon.AG, the laboratoire national de pathologie aviaire (LNPA) of Ploufragan France. The serum quality was checked using a negative SPF avian serum, a positive serum against Mycoplasma gallisepticum $\mathrm{Mg} 15$.

$25 \mu 1$ of serum and $25 \mu 1$ of antigen are put on a glass slide previously washed, rinsed and dried. The antigen and serum are mixed at room temperature of the reaction is carried out according to Stanley et al., 2001.

Mycoplasma isolation: The reference strain of MG used is MGATTC 15302 produced in rabbit and kindly supplied by the LNPA, France.

About $0.5 \mathrm{~g}$ of tissues (tracheas, lungs and air sacs) are cut in small pieces and ground in a sand bath containing $5 \mathrm{ml}$ of mycoplasma medium.

$0.2 \mathrm{ml}$ of this suspension is inoculated in Frey`s liquid medium. When a color change is observed in the liquid medium, another inoculation of a fresh liquid medium is perform.

Later on an inoculation of Frey`s solid medium is carried out after a color changing had occurred in the liquid medium. If no color changing has occurred in the liquid medium a subculture is done on a solid medium because it is well known that mycoplasmas are very slow-growing microorganisms (Kleven, 2008). If Mycoplasma growth is noted on solid medium, agar blocks containing colonies are transferred in tubes of liquid medium for mycoplasmas cloning (Stipkovits et al., 1975).

Positive cultures were characterized by Dienes staining, biochemical and growth inhibition tests using $\mathrm{MG}$ antiserum produced in rabbit kindly supplied by Dr Bouchardon.A.G.

\section{Results}

Serology: Among 148 tested sera, 123 were positive representing a rate of infection of $83.10 \%$ showing the strong spread of MG. However, the rate of infection was slightly higher in broiler-chickens $(84.81 \%)$ than in laying hens $(81.15 \%)$ (Table I).

The highest prevalence (100\%) of MG infection was found in the present study in El Madher, Ain yagout and Boumia (TableII) Seasonal variation of prevalence of MG infection was observed in the present study. The prevalence was higher $(91.13 \%)$ in winter season and lower (73.91\%) in summer season (Table III).

According to the age, the highest prevalence of MG infection was $86.95 \%$ in chicks whereas lowest prevalence was $82.35 \%$ in adult (Table IV).

Bacteriology: 143 mycoplasmas strains were isolated from 237 organ samples representing a positivity rate of $60.33 \%$.

Table-2. Seroprevalence of Mycoplasma gallisepticum according to the study area

\begin{tabular}{lccc}
\hline Study area & Number of samples & Number of positive sera & Rate of SPA \% \\
\hline El Madher & 6 & 6 & 100 \\
Tazoult & 16 & 15 & 93.75 \\
Arris & 7 & 5 & 71.42 \\
Ain Touta & 40 & 25 & 62.5 \\
Ain Yagout & 6 & 6 & 100 \\
Oued Chaaba & 32 & 30 & 93.75 \\
Djerma & 10 & 8 & 80 \\
Merouana & 7 & 6 & 85.71 \\
Boumia & 13 & 13 & 100 \\
Batna & 11 & 9 & 81.81 \\
Total & 148 & 123 & - \\
\hline
\end{tabular}


Incidence of Avian Mycoplasmosis in the region of Batna, Eastern Algeria

Table-3. Seasonal seroprevalence of Mycoplasma gallisepticum infection

\begin{tabular}{lcccc}
\hline Season & Tested sera & Positive sera & Negative sera & Rate of positive sera \\
\hline winter & 79 & 51 & 18 & $73.91 \%$ \\
summer & 69 & 72 & 7 & $91.13 \%$ \\
\hline
\end{tabular}

Table-4. Seroprevalence of Mycoplasma gallisepticum in chickens according to age

\begin{tabular}{lccc}
\hline Age & Number of samples & Positive cases & Negative cases \\
\hline Chicks & 46 & $40(86.95 \%)$ & 06 \\
Adults & 102 & $84(82.35 \%)$ & 18 \\
\hline
\end{tabular}

31 strains were identified as MG $(21.67 \%)$. The

MG distribution was as follows: 3 in laying hens and 28 in broiler-chickens representing $2.09 \%$ and $19.58 \%$ respectively (Table I).

It should be stated that all flocks either laying hens or broiler-chickens harbor MG.

\section{Discussion}

The serological test in this study, for instance the rapid serum agglutination (RSA) may lack specificity and/or sensitivity. Therefore, its use is strongly recommended for monitoring flocks rather than for testing individual birds. For this reason we had tried to establish the test sensitivity and specificity under our laboratory conditions by using fresh sera. The latter had been decomplemented in order to ovoid cross reactions between $\mathrm{MG}$ and $\mathrm{MS}$ and diluted to 1/5. The evaluation of the RSA test was validated using known positive and negative control sera. In our study the size of tested samples is similar to that reported by several others ranging between 10 and 30 birds (Boucetta et al., 1997; Kermorgant, 1998 and Sabir, 2003).

This study has revealed a very high prevalence of Mycoplasma gallisepticum infection either in laying hens or in broiler-chickens in Batna region. Our results are higher than those of similar studies.

For instance, Thai et al. (2009) and Papanikolaou (2002) found a rate of infection of $37.83 \%$ and $21 \%$ respectively. However, our findings are slightly in accordance with those of Wunderwald et al. (2002), Sarkar et al. (2005) and Hossain et al. (2007) with a rate of infection of $75 \%, 58.90 \%$ and $55.13 \%$ respectively.

Concerning broiler-chickens, $84.81 \%$ of the flocks are MG infected (Table I). This value is greatly higher than results obtained by Baruta et al. (2001) and Aimeur et al. (2010) (1.25\%, 30\%). However, our results are in accordance with those obtained by orajaka et al. (2002) and mainly those of Evans et al. (2009) with a positivity rate of $64.9 \%$ and $100 \%$ respectively.
For laying hens, in a study Nascimento et al. (2005) found a rate of infection by MG of about $90 \%$. A similar study conducted in Bangladesh showed that the rate of infection varies from $45.1 \%$ to $66.5 \%$ (Hossain et al., 2010; Barua et al., 2006). These results are higher than those in the present study.

This study has revealed a sharp influence of season on the incidence of avian infection by $\mathrm{MG}$ (Table III). Indeed, rate of infection of $90 \%$ has been noted during winter, compared to that of $73.91 \%$ obtained during summer. These results are in accordance with those of Sikder et al. (2005), Sarkar et al. (2005) and Hossain et al. (2010).

The effect of age on the occurrence of mycoplasmal infection is revealed in the study with a rate of infection of $69.9 \%$ and $48.7 \%$ in adult and young birds respectively (Table II).

In the present study, MG has been isolated at a rate of $21.67 \%$ (Table $\mathrm{V}$ ). This rate is higher than to those found by Helail, 1998 (11.89\%).

The results of mycoplasma isolation from different organs showed that air sacs are the main site of multiplication of this microorganism from dead birds $(90 \%)$. Similar result was also obtained by Helail, 1998 (36.29\%) and Shaker, 2005 (92\%). Lungs are the second site of isolation $(71.42 \%)$ followed by tracheas $(62.93 \%)$.

MG isolation rate from tracheas $(62.96 \%)$ is higher than to those obtained by Paakpinyo and Sasipreeyajan, 2007; Feberwee et al., 2005 and Gharaibeh and Al Roussan, 2008 (44.66\%, 33\% and $31.6 \%$ respectively).

Results obtained in our study revealed that the isolation rate of $\mathrm{MG}$ from the lungs is higher than in others studies (shaker, 2005; Helail, 1998).

The discordance observed between serology and isolation may be attributed to different factors such as the existence of tissular inhibitors of mycoplasma growth (Boussetta et al., 1997), the use of dry swabs reducing the viability of microorganisms (Zain et al., 1995), the absence of localization of mycoplasmas 
Incidence of Avian Mycoplasmosis in the region of Batna, Eastern Algeria

Table-5. I solation of Mycoplasma gallisepticum from different type of sampled

\begin{tabular}{lcccc}
\hline Organsamples & samples & Positive digitonin & Rate of mycoplasmas & Rate of MG \\
\hline Tracheas & 100 & 27 & $27 \%$ & $62.96 \%$ \\
Lungs & 64 & 7 & $10.94 \%$ & $71.42 \%$ \\
Air sacs & 73 & 10 & $13.70 \%$ & $90 \%$ \\
\hline
\end{tabular}

especially MG in some sites after initial infection (Takase et al., 2000; Kempf et al., 1998), the difficulty of isolating mycoplasmas after some antibiotics treatment (Aimeur et al., 2010).

\section{Acknowledgement}

The authors are thankful to the Laboratory of microbiology, Institute for Animal Science and Agricultural Sciences, University Batna, Algeria and Dr Bouchardon.A.G from the laboratoire national de pathologie aviaire (LNPA) of Ploufragan, France for providing some facilities to conduct the present research work

\section{References}

1. Aimeur R, Bouaziz O., Kabouia R, Bererhi H. (2010): Prévalence de Mycoplasma gallisepticum et de Mycoplasma synoviae dans les élevages avicoles de l'Est Algérien. Rev. Med. Vet. 161(3): 141-145.

2. Amin MM and Jordan FTW. (1979): Infection of the chicken with a virulent or avirulent strain of Mycojplasma gallisepticum alone and together with Newcastle disease virus of E. coli or both. Vet Microbiol. 4: 35-45.

3. Amin MM, Sidique MAB and Rahman MM. (1992): Investigation on chronic respiratory disease in chickens: part-II. BUA Res. Progress. 6: 519-526.

4. Barua S R., Prodhan A M, Islam S and Chowdhury S. (2006): Study on Mycoplasma Gallisepticum in Chickens in Selected Areas of Bangladesh. Bangl. J. Vet. Med. 4: 141-142.

5. Baruta D A, Ardoino S M, Marengo M L. (2001): A survey in infections caused by Mycoplasma synoviae and Mycoplasma gallisepticum in broiler chickens slaughtered in General Pico using the Slide Quick Agglutination technique. Ciencia.Vet. Facultad de Ciencias Veterinarias. UNLPam.

6. Behbahan G G N, et.al.(2005): Isolation and detection of Mycoplasma gallisepticum by polymerase chain reaction and restriction fragment length polymorphism. Iranian J.Vet. Res. 6(2): 35-41.

7. Boussetta M, Chaouachi N, Mlik B. (1997): Etude sérologique et bactériologique des mycoplasmoses aviaires dans la région du Cap Bon en Tunisie. Rev.Elèv.Med.Vet. Pays Trop. 50: 93-96.

8. Bradbury JM. (2001): Avian Mycoplasmosis. In: Poultry Diseases.5th ed. Jordan.D. and Raragher T. EDS. W.b. Sanders? London, UK, 178-193.

9. Evans J D, Thornton D L, Branton SL. (2009): Diagnosis of Mycoplasma gallisepticum from a broiler breeder flock: comparison of three diagnostics methods. International Journal of Poult Sci. 8: 104-107.

10. Feberwee A., et.al.(2005): Comparison of Culture, PCR, and Different Serologic Tests for Detection of Mycoplasma gallisepticum and Mycoplasma synoviae Infections. Avian Dis. 49:260-268.
11. Frey M L, Hanson R P and Anderson D P. (1968): A medium for the isolation of avian mycoplasmas. Am. J. Vet.Res. 29: 2163-2171.

12. Ghoraibeh S and Al Roussan D. (2008): the use of molecular techniques in isolation and characterization of Mycoplasma gallisepticum from commercial chickens in Jordan. Int. J. Of Poult.Sci. 7:28-35

13. Gordon R.F. (1979)Pathologies des volailles. Maloine S. A. Editeur, pp. 267.

14. Helail S S S. (1998): Evaluation of mycoplasma antigens used for the detection of mycoplasma infection in chicken. Thesis presented for master degree, Cairo Univ. Egypt, pp.45.

15. Hossain K M M, Ali M Y and Haque M I. (2007): Seroprevalence of mycoplasma gallisepticum infection in chicken in the greater rajshahi district of bangladesh. Bangl. J. Vet. Med. 5: 09-14.

16. Hossain K M M, Hossain Md T, Yamato I. (2010): Seroprevalence of Salmonella and Mycoplasma gallisepticum Infection in Chickens in Rajshahi and Surrounding Districts of Bangladesh. Int. J.Biol. 2, 74-80.

17. Hudson P, et.al.(2006): Identification of avirulenc associated determinant, dihydrolipoamide dehydrogenase (lpd), in Mycoplasma gallisepticum through in vivo screening of transposon mutants. Infect. Immun. 74: 931-939.

18. Kempf I, et.al.(1998): Mycoplasmose à Mycoplasma gallisepticum: réalisation d'un modèle expérimental rôle de l'ammoniac comme facteur d'exacerbation. Avian Pathol. 17: 601-616.

19. Kermorgant P. (1999): Les mycoplasmoses aviaires: enquête sérologique réalisée en Bretagne en 1998. Thèse de docteur vétérinaire Faculté de Médecine Vétérinaire Nantes, pp.131.

20. Kleven S H. (2008): Control of Avian Mycoplasma Infections in Commercial Poultry. Avian Dis. 52: 367-374.

21. Ley D H. (2003): mycoplasma gallisepticum infection. In: diseases of poultry. Saif Y.M., Barnes.H.J., Glisson J.R., Fadly A.M., Mc Dacgald L.R. and Swane D.E. eds Iowa State University Press, Ames, Iowa, USA 41-52.

22. Nascimento E R, et.al.(2005): Eradication of Mycoplasma gallisepticum and $M$. synoviae from a chicken flock by antimicrobial injections in eggs and chicks. Acta.Sci.Vet. 33: 119-124.

23. Nunoya TT, et.al.(1995): Occurrence of keratoconjunctivitis apparently caused by Mycoplasma gallisepticum in layer chickens. Vet. Pathol. 32: 11-18.

24. Orajaka L J E, Okoye J O A, Oboegbulem S I. (2002): Seroepidemiologic survey of mycoplasmal infections in native and exotic chickens in Nsukka District of South Eastern Nigeria. J.Sustainable.Agric.Environ. 4: 77-82.

25. Pakpinyo S and Sasipreeyajan J. (2007): Molecular characterization and determination of antimicrobial resistance of Mycobacterium gallisepticum isolated from chickens. Veterinary Microbiol. 125: 59-65.

26. Papanikolaou J N. (2002): Epidemiological investigation of Mycoplasmas, M. gallisepticum, M. synoviae and M. meleagridis in poultry flocks in Greece. Journal of the hellenic veterinary medical society, 53: 297-303. 
27. Poveda J B, et.al.(1990): An Epizootiological Study of Avian Mycoplasmas in Southern Spain. Avian Pathol. 19: 627-633.

28. Rozina A. 2000: studies on the development of a vaccine using indigenous strains of Mycoplasma gallisepticum. Thesis of doctor of philosophy degree. Department of microbiology, University of Karashi, Pakistan.

29. Sabir J. (2003): Enquête sérologique sur Mycoplasma gallisepticum et Mycoplasma synoviae dans les élevages de poules pondeuses. Thèse de Docteur Vétérinaire, IAV Hassan II, Maroc, (2003), 110 pages.

30. Sarkar S K, et.al.(2005): Sero-Prevalence of Mycoplasma gallisepticum Infection of Chickens in Model Breeder Poultry Farms of Bangladesh. Int.J. Poult. Sci. 4: 32-35.

31. Sikder A J, et.al. (2005): Seroprevalence of Salmonella and Mycoplasma gallisepticum Infection in the Six Model Breeder Poultry Farms at Patuakhali District in Bangladesh. Int.J. Poult. Sci. 4: 905-910.

32. Stanley W A, et.al.(2001): Monitoring Mycoplasma gallisepticum and Mycoplasma synoviae infection in breeder chickens after treatment with enrofloxacin. Avian Dis. 145: 534-539.
33. Stipkovits L, El-ebeedy A A, Kisary J and Varga L. (1975): Mycoplasma infection of geese I. incidence of Mycoplasmas and Acholeplasmas in geese. Avian pathoL. 4: 35-43.

34. Takase K, et.al.(2000): Serological monitoring on layer farms with specific pathogen free chickens. J.Vet.Med.Sci. 62: 1327-1329.

35. Thái T H, ?c N N, Giáp N V, Hýõng C T T. (2009): Sero Prevalence of Mycoplasma gallisepticum Infection in Chicken Ross 308 and Colour ISA Raised in Some Provinces in The North of Vietnam. T?p chí Khoa h?c và Phát tri?n, T? $7: 306-313$.

36. Villate D, 2001. Maladies des volailles. Éditions France agricole, $2^{\text {ème }}$ édition, pp399.

37. Wunderwald C and Hoop R K. (2002): Serological monitoring of 40 Swiss fancy breed poultry flocks. Avian Pathol.31: 157-162.

38. Zain Z M, Bradbury J M. (1995): The influence of type of swab and laboratory method on the recovery of Mycoplasma gallisepticum and Mycoplasma synoviae in broth medium. Avian pathol. 24: 707-716. 